\title{
Anestesia do pirarucu por aspersão direta nas brânquias do eugenol em solução aquosa
}

\author{
Anesthesia in pirarucu by eugenol sprays in the gills
}

\author{
Alexandre Honczaryk ${ }^{I}$ Luís Antonio Kioshi Aoki Inoue ${ }^{\mathrm{II}}$
}

\section{- NOTA -}

\section{RESUMO}

O pirarucu (Arapaima gigas) é um peixe que vem ganhando importância cada vez maior na piscicultura comercial na Amazônia. No entanto, por ser um animal de grande porte, no campo, é comum o relato de acidentes envolvendo pancadas violentas em técnicos durante o manejo. Desse modo, é imperativa a anestesia desses animais. Todavia, para a espécie em discussão, a realização de banhos anestésicos, muitas vezes, não é possível devido ao tamanho do animal e ao risco de afogamento do peixe pulmonado. O presente trabalho avaliou de maneira prática a viabilidade do eugenol como anestésico para o pirarucu por aspersão direta nas brânquias. Para tanto, três animais jovens foram submetidos à aspersão de eugenol nas brânquias em concentração de $30 \mathrm{mg} \mathrm{L}^{-1}$ e dois na concentração de $60 \mathrm{mg} \mathrm{L}^{-1}$. O eugenol borrifado nas brânquias mostrou-se viável como anestésico para o pirarucu, não sendo observada a mortalidade de animais mesmo um mês após os testes.

Palavras-chave: peixe, Arapaima gigas, manejo, anestésico, respostas.

\section{ABSTRACT}

Pirarucu (Arapaima gigas) is an important species to commercial fish farming in Amazon. It achieves more than $2 m$ and $100 \mathrm{~kg}$. However, fish handling may be risky to workers. Anesthesia is necessary, but usual anesthetic baths are not feasible due to the size of fish and the pulmonary respiration of Pirarucu. This fish may die drowned in anesthetic baths. This research evaluated the alternative anesthetic eugenol to pirarucu by sprays in the gills. Solution in concentration of $30 \mathrm{mg} \mathrm{L}^{-1}$ was sprinkled in the gills of three fish, and $60 \mathrm{mg} \mathrm{L}^{-1}$ was sprinkled in the gills of two other fish. Eugenol sprays provided safe anesthesia for pirarucu. No mortality was observed even one month after the experiment.
Key words: fish, Arapaima gigas, management, anesthetic, responses, metabolism.

O pirarucu é o maior peixe de água doce do mundo. Ele pode atingir mais de $2 \mathrm{~m}$ de comprimento e $100 \mathrm{~kg}$, sendo sua carne muito apreciada nos mercados consumidores do Norte do Brasil (GOULDING, 1980). O cultivo comercial dessa espécie vem crescendo na Amazônia, apresentado ainda índices interessantes, principalmente no que concerne ao crescimento (GANDRA et al., 2007). Em condições de cativeiro, o pirarucu pode atingir mais de $10 \mathrm{~kg}$ em menos de um ano de idade (IMBIRIBA, 2001). Entretanto, devido ao grande porte dos espécimes, a realização de práticas de manejo como biometria, injeções, coleta de sangue, marcação e, mais recentemente, o uso de ultra-som para avaliação de estágios reprodutivos é tarefa de grande risco de acidentes, sendo diversos os relatos no campo de pancadas violentas em pesquisadores e trabalhadores rurais.

O eugenol é um anestésico alternativo para peixes bastante divulgado nos últimos tempos por ser um produto natural. Esse é o principal componente do óleo-de-cravo e de vários outros óleos essenciais extraídos de plantas amazônicas, apresentando poucos riscos ao ambiente e aos animais (CHO \& HEATH, 2000; INOUE et al., 2003; IVERSEN et al., 2003; TORT et al., 2002). A eliminação do eugenol do tecido comestível

ICoordenadoria de Pesquisas em Aquicultura, Instituto Nacional de Pesquisas da Amazônia (Inpa). Manaus, AM, Brasil.

IE Embrapa Amazônia Ocidental, Empresa Brasileira de Pesquisa Agropecuária, Rod. AM 010, km 29, Zona Rural, 69010-970, Manaus, AM, Brasil. E-mail: luis.inoue@cpaa.embrapa.br. Autor para correspondência. 
em peixes pré-expostos é em torno de 12h (KILDEA et al., 2004). Além disso, o eugenol é um produto de uso interno consagrado na odontologia como componente (misturado ao óxido de zinco) de preenchimentos temporários para restaurações (INOUE et al., 2003).

O presente trabalho avaliou de forma simples o eugenol como anestésico para o pirarucu. Foi anotado o tempo para a perda total de equilíbrio, o tempo disponível para o manejo e o tempo de recuperação anestésica. Informações elementares serão fornecidas aos técnicos da área de piscicultura, bem como para pesquisadores e comitês de ética em experimentação com animais, em especial para peixes (CCAC, 2005).

Cinco animais jovens $(6,1 \pm 1,8 \mathrm{~kg}$ e $86,4 \pm 10,4 \mathrm{~cm}$ ) foram submetidos à anestesia por aspersão direta de soluções aquosas de eugenol nas brânquias, sendo que três receberam a dosagem de $30 \mathrm{mg} \mathrm{L}^{-1}$ e dois $60 \mathrm{mg} \mathrm{L}^{-1}$. O eugenol utilizado no presente trabalho foi previamente diluído em etanol na proporção de 1:20 devido às suas características hidrofóbicas (INOUE et al., 2003). Em seguida, foram adicionadas as respectivas quantidades necessárias (1,2 e 2,4ml) da solução alcoólica (contendo 50mg mL $\mathrm{mL}^{-1}$ de eugenol) em garrafas de 2l, contendo água limpa, sem cloro, aclopadas a um borrifador manual, de uso comum em jardinagem.

A solução aquosa de eugenol foi aspergida diretamente nas brânquias dos pirarucus até a observação de saturação aparente das lamelas, quando o excesso de líquido escorria para fora da cavidade opercular. Os animais permaneceram fora da água, protegidos da luz solar e mantidos úmidos, jogando-se água na superfície do corpo. Foram observados: 1) tempo em minutos para a perda total de equilíbrio, caracterizada pela incapacidade de apoio do abdômen no chão - tempo em que os peixes tombavam lateralmente; 2) tempo em que os peixes apresentavam ausência de reações a estímulos, caracterizado pela ausência de movimentos dos peixes durante o manuseio; e 3) tempo para a primeira tomada de ar voluntária, após a lavagem das brânquias por aspersão de água limpa, sem a adição de qualquer produto e estocagem temporária dos animais em piscina de fibra de vidro. Os peixes foram pesados e medidos em condições de sedação em balança suspensa e trena esticada sob uma mesa. Após o experimento, os peixes foram retornados ao viveiro de origem.

O método de aspersão do anestésico diretamente nas brânquias do pirarucu é importante devido à pouca viabilidade de serem realizados banhos anestésicos em animais grandes. Ainda por essa espécie ter respiração aérea obrigatória, o pirarucu apresenta freqüência de batimentos operculares relativamente baixa, quando em água de má qualidade ou em presença de compostos xenobióticos, o que dificulta a chegada do anestésico na corrente sanguínea e a depressão do sistema nervoso central. O risco de afogamento do peixe pulmonado também deve ser considerado em banhos anestésicos, pois o pouco de solução anestésica que chegaria às brânquias poderia ser suficiente para atordoar o animal, de forma que ele não conseguiria subir a coluna de água para respirar.

O número reduzido de animais e o teste somente de doses baixas neste trabalho são explicados pelo custo extremamente alto de cada peixe utilizado. Além disso, a ausência de informações prévias a respeito de produtos e procedimentos para anestesia em pirarucu representava risco elevado de perda de animais.

O eugenol mostrou-se viável como anestésico para o pirarucu, proporcionando a segurança necessária aos técnicos durante o manejo. Aparentemente, os animais sofreram estresse mínimo, visto que a natação, a coloração e a aceitação de ração estavam normais já poucas horas após o manejo. Não foram registrados animais mortos mesmo um mês após o experimento. $\mathrm{Na}$ dose de $30 \mathrm{mg} \mathrm{L}^{-1}$, as respostas do pirarucu foram mais lentas tanto para a indução quanto para a recuperação à anestesia. A dose de $60 \mathrm{mg} \mathrm{L}^{-1}$ possivelmente proporcionou maior quantidade do produto nas lamelas branquiais mais rapidamente e, conseqüentemente, entrada mais ágil na corrente sanguínea e depressão do sistema nervoso central (Tabela 1).

Os tempos de indução à anestesia, ausência de reações a estímulos e recuperação anestésica do pirarucu foram semelhantes aos observados em outras espécies de peixes tropicais, anestesiados com eugenol em doses similares (BARBOSA et al., 2007; INOUE et al., 2003; ROUBACH et al., 2005). O tempo disponível para o manejo proporcionado pelo eugenol foi relativamente curto também para o pirarucu, mas o suficiente para a realização de práticas de manejo rápidas, de duração abaixo de dois minutos como biometria, injeções e marcação. De acordo com os autores citados anteriormente, mesmo se as concentrações do eugenol fossem aumentadas, pouco se prolongaria o tempo disponível para o manejo (2-3 minutos). Esse aumento de dosagem proporcionaria a indução à anestesia mais rápida e não a indução à anestesia mais duradoura, que estaria relacionada à irrigação/saturação por mais tempo das lamelas pelo anestésico. Além disso, os riscos por superdosagens, como danos branquiais, conseqüências metabólicas e óbitos, também aumentariam (INOUE et al., 2003; BARBOSA et al., 2007; IVERSEN et al., 2003; TORT et al., 2002).

Ciência Rural, v.39, n.2, mar-abr, 2009. 
Tabela 1 - Observações práticas durante a anestesia do pirarucu (Arapaima gigas) por aspersão de eugenol em solução aquosa diretamente nas brânquias.

\begin{tabular}{|c|c|c|c|c|c|c|}
\hline \multirow[b]{2}{*}{ Peixe } & \multirow[b]{2}{*}{ Peso* $^{*}(\mathrm{~kg})$} & \multirow[b]{2}{*}{$\begin{array}{l}\text { Comprimento* } \\
\text { (cm) }\end{array}$} & \multirow[b]{2}{*}{$\begin{array}{l}\text { Concentração da } \\
\text { solução de eugenol } \\
\left(\mathrm{mg} \mathrm{L}^{-1}\right)\end{array}$} & \multicolumn{3}{|c|}{--------------------------Tempo (minutos) -------------------------- } \\
\hline & & & & $\begin{array}{l}\text { Perda total de } \\
\text { equilíbrio }\end{array}$ & $\begin{array}{c}\text { Ausência de } \\
\text { reação/tempo } \\
\text { disponível para } \\
\text { manejo }\end{array}$ & $\begin{array}{c}\text { Primeira tomada de ar } \\
\text { voluntária após lavagem } \\
\text { das brânquias para } \\
\text { recuperação }\end{array}$ \\
\hline 1 & 9,0 & 96 & 30 & 1,1 & 5 & 22 \\
\hline 2 & 3,8 & 69 & 30 & 1,2 & 3 & 4 \\
\hline 3 & 6,0 & 92 & 30 & 1,1 & 2 & 6 \\
\hline 4 & 6,0 & 88 & 60 & 0,5 & 2 & 4 \\
\hline 5 & 5,8 & 87 & 60 & 0,5 & 2 & 1,2 \\
\hline
\end{tabular}

* Os peixes foram pesados e medidos em condições de sedação.

$\mathrm{Na}$ necessidade de anestesia mais prolongada para o pirarucu, um sistema de aspersão intermitente de anestésico nas brânquias pode ser interessante, de forma que assim seria possível saturar as lamelas com anestésico sem riscos de afogamento do peixe pulmonado. Comparativamente, mesas cirúrgicas, utilizadas em estudos de fisiologia em peixes de respiração branquial, são equipadas com sistemas de minireservatórios, bombas e tubulações de diâmetro reduzido, que irrigam as brânquias com soluções anestésicas durante os procedimentos cirúrgicos, que duram de 15 a 20 minutos aproximadamente (SUNDIN et al., 1999). O teste de outros produtos anestésicos como a benzocaína, a tricaína metanosulfonato (MS222) e o metomidato, bem como a prova de indução à anestesia por injetáveis (por exemplo, xilazinas) e inaláveis (por exemplo, halotano e óxido nitroso), é ainda necessária para o pirarucu. Porém, para isso, ainda há o risco de morte de animais.

O eugenol aspergido diretamente nas brânquias proporciona anestesia segura do pirarucu. Além disso, práticas de manejo de curta duração podem ser feitas com baixo risco de acidentes no campo. Novos estudos, entretanto, devem ser conduzidos para a avaliação das respostas metabólicas da espécie ao anestésico testado.

\section{AGRADECIMENTOS}

Conselho Nacional de Desenvolvimento Científico e Tecnológico (CNPQ) (471263/07-9) e Financiadora de Estudos e Projetos (FINEP) (Projeto Desenvolvimento de Pesquisa em Processos e Produtos Agropecuários Aplicados ao Agronegócio Familiar, FAPEAM/CPAA/DESPA).

\section{REFERÊNCIAS}

BARBOSA, L.M.G. et al. Respostas metabólicas do matrinxã (Brycon amazonicus) submetido a banhos anestésicos de eugenol. Acta Scientiarum Biological Sciences, Maringá, v.29, n.3, p.255-260, 2007.
CCAC. CANADIAN COUNCIL ON ANIMAL CARE. CCAC guidelines on the care and use of fish in research, teaching and testing. 2.ed. Ottawa, 2005. 94p.

CHO, G.K.; HEATH, D.D. Comparison of tricaine methanesulphonate (MS222) and clove oil anaesthesia effects on the physiology of juvenile chinook salmon Oncorhynchus tshawytscha (Walbaum). Aquaculture Research, Oxford, v.31, p.537-546, 2000.

GANDRA, A. et al. Pirarucu growth under different feeding regimes. Aquaculture International, Amsterdan, v.15, p.9196, 2007.

GOULDING, M. The fishes and the forest: explorations in Amazonian Natural History. Berteley: University of California, 1980. 200p.

IMBIRIBA, E.P. Potencial da criação de pirarucu, Arapaima gigas, em cativeiro. Acta Amazonica, Manaus, v.31, n.2, p.299-316, 2001.

INOUE, L.A.K.A. et al. Clove oil as anaesthetic for juveniles of matrinxã Brycon cephalus (Gunther, 1869). Ciência Rural, Santa Maria, v.33, n.5, p.943-947, 2003.

IVERSEN, M. et al. The efficacy of metomidate, clove oil, aqui-s and benzoak as anesthetics in atlantic salmon (Salmo salar L.) smolts, and their potential stress-reducing capacity. Aquaculture, Amsterdam, v.221, p.549-566, 2003.

KILDEA, J. et al. Accumulation and clearance of the anesthetics clove oil and Aqui-S ${ }^{\mathrm{TM}}$ from the edible tissue of silver perch (Bidyanus bikyanus). Aquaculture, Amsterdam, v.232, p.265277, 2004.

ROUBACH, R. et al. Eugenol as an efficacious anesthetic for tambaqui, Colossoma macropomum (Cuvier). Aquaculture Research, Oxford, v.36, p.1056-1061, 2005.

SUNDIN, L.I. et al. Cardiovascular and respiratory reflexes: the tropical fish, traíra (Hoplias malabaricus) $\mathrm{O}_{2}$ chemoresponses. Respiration Physiology, Bochum, v.116, p.181-199, 1999.

TORT, L. et al. Cortisol and haematological response in sea bream and trout subjected to the anesthetics clove oil and 2phenoxyethanol. Aquaculture Research, Oxford, v.33, p.907-910, 2002. 